\title{
HEAT TRANSFER AND PRESSURE DROP EVALUATION IN THIN WEDGE - SHAPED TRAILING EDGE
}

\author{
C. Carcasci, B. Facchini, L. Innocenti \\ Università degli Studi di Firenze \\ Dipartimento di Energetica "Sergio Stecco" DE \\ Via Santa Marta, 3 \\ 50139 Firenze - ITALY \\ e-mail: inno@brun.de.unifi.it
}

\begin{abstract}
In modern high loaded transonic turbines the aerodynamic losses of turbine airfoils are mostly covered by the thickness and the wedge angle of the blade trailing edges. Due to the aerodynamic requirements the thin trailing edges are the life limiting parts of the airfoils. The aerodynamic design requirements lead to trailing edge slots with extreme aspect ratio and huge fillet radius in relation to the internal slot geometry.

In most cases, the conventional design tools are not validated for these geometries, therefore an improved knowledge of flow and heat transfer in this area is necessary.

This paper discusses the measurements of endwall heat transfer coefficient and pressure drops in a wedge-shaped duct with two different turbulators arrangement. The first one is concerning five different long ribs (pedestals) configurations disposed streamwise while the other one is related to three configurations of staggered pin fins. Pedestals and pin fins stand vertically on the bottom surface of the wedge - shaped duct. This surface, named endwall, is coated with a thin layer of thermochromic liquid crystals and several transient tests are run to obtain detailed heat transfer coefficient distributions. Both for the pedestal and pin fins several parametric studies has been performed, varying both Reynolds number range (from 9000 to 27000) and turbulators configurations while outlet Mach number was set to 0.3 for all tests. Investigated pedestal configurations are different for turbulators spanwise pitch while pin fins geometry have different pin diameter values. In all cases the wedge duct angle is $10^{\circ}$.
\end{abstract}

Results indicate that the smallest long ribs pitch and pin fin diameter are most recommended because of its significant endwall heat transfer and moderate pressure-drop penalty.

Long ribs and pin-fins are aluminium made in order to evaluate an average value of the heat transfer coefficient on their side surface. So a valuation of global heat transfer coefficient in the internal trailing edge cooling duct become possible.

\section{INTRODUCTION}

Nowadays in the aero engine and gas turbine industries there is an increasing demand for more efficient and powerful gas turbine engines and for a reduction in weight, cost and design time scales. At the same time environmental, safety and reliability requirements become very restrictive. In order to achieve these goals, turbine firing temperature increased rapidly in the last years, enabled by the extensive use of cooling technology. Many researchers and industry R\&D sectors base their activity on developing and improving cooling techniques and on appropriate cooling design tools definition. On the other hand in modern transonic high loaded gas turbines as in low pressure turbines, higher efficiency and weight reduction requirements determine lower airfoil thickness, particularly in the Trailing Edge (TE) zone. Although casting and solidification improvements allow blade manufacturing with very thin TE, ducts area reduction and aspect ratio increase make hard the design of efficient cooling systems. So the interaction between manufacturing and cooling appears to be a key element of blade 
design procedure.

A TE cooling system is based on small axial ducts with inserted turbulators, like pin fins or pedestals. These solutions allow both a heat transfer and a blade TE solidity enhancement. Generally a heat transfer knowledge based on research state of the art $(1,2,3,4,5,6,7,8,9)$ is enough to design reliable cooling systems for standard thickness blade TE, but often for very thin TE the conventional design tools result not validated. In these cases an improved knowledge of flow and heat transfer is mandatory. Moreover the effects of pin fins and pedestals are often evaluated only in terms of endwall average heat transfer coefficient, while the turbulators surface contribution is often neglected $(10,11,12)$. On the contrary a global evaluation of heat transfer process is fundamental in actual cooled blade design, considering that all the numerical design procedures base themselves on experimental correlation or database to evaluate heat transfer coefficients and pressure drops.

Present study is concerning two different cooling system geometries based on long pedestals and pin fins in a wedgeshaped duct, representing typical geometrical arrangements of an advanced cooled gas turbine vane or blade. The Reynolds number range used in experimental tests and the characteristic geometrical parameters were chosen in order to get useful information for design process and to develop significant empirical correlation.

The use of TLC technique is coupled with an innovative solution to evaluate the surface - averaged contribution of the turbulators to the global heat transfer coefficient. Being indeed pedestals and pin fins aluminium made, it is possible to estimate entering heat flux.

\section{NOMENCLATURE}

A section

$c_{p} \quad$ specific heat

d pin diameter

$\mathrm{D}_{\mathrm{h}} \quad$ hydraulic diameter

$[\mathrm{m}]$

h heat transfer coefficient

k conductivity

$\left[\mathrm{W} \cdot \mathrm{m}^{-1} \cdot \mathrm{K}^{-1}\right]$

$\mathrm{K}_{\mathrm{s}} \quad$ pressure factor

L duct length

$[\mathrm{m}]$

m mass flow rate

$\mathrm{N} \quad$ pin row number

$\mathrm{p} \quad$ wet perimeter

$\mathrm{p}_{0} \quad$ total pressure

Pr Prandtl number

Re Reynolds number

$\mathrm{s}_{\mathrm{x}} \quad$ streamwise pitch

$\mathrm{S}_{\mathrm{y}} \quad$ spanwise pitch

$\mathrm{t}$ time

$\mathrm{T}$ temperature

$\mathrm{T}_{8} \quad$ mainstream flow

v velocity

[m]

[s]

$[\mathrm{K}]$

[K]

$\left[\mathrm{m} \cdot \mathrm{s}^{-1}\right]$
$\mathrm{X}$

abscissa

[m]

Greek

$\begin{array}{ll}\rho & \text { density } \\ \mu & \text { dynamic viscosity }\end{array}$

$\left[\mathrm{kg} \cdot \mathrm{m}^{-3}\right]$

[Pa.s ]

\section{Subscripts}

i initial

IN inlet

MAX maximum

OUT outlet

w wall

\section{EXPERIMENTS}

TLC are organic substances characterized by particular properties: they display colour in response to temperature changes as a results of reorientation of the crystals accompanied with selective reflection of illuminating light Generally the analyzed surface is sprayed with liquid crystals and then black background paints. These coatings are sprays of thickness of the order of $10 \mu \mathrm{m}$. Within the test range specified by the manufacturer, the wide - band TLC displays a colour in the sequence of red, green and blue. Outside the test range, the TLC are colourless.

The use of TLC technique in heat transfer analysis starts in the 70's then several researchers extended this technique to blade cooling studies being not intrusive and able to assure a high level of accuracy and a detailed description of Heat Transfer Coefficient (HTC).

Two different solutions are possible for HTC determination with this technique: steady state and transient.

In the present work transient technique is used. It is carried out by suddenly exposing the hot air to the test section, which results in a colour change of the surface coatings $(3,13$, $14,15,16)$. The liquid crystals are colourless at room temperature, then their hue change to red, green, blue and finally colourless again during the heating process. TLC colour changing is recorded by means of a digital camcorder, hence the acquired film is elaborated together with hot air temperature history measured by means of several thermocouples. All the numerical procedure is based on the condition that the heat conduction along the solid surface is 1-D. This condition requires a very low conductivity material with high thickness.

The very low values of TLC activation temperature (close to $300-320 \mathrm{~K}$ ) require a similitude approach to correctly use the experimental results. Moreover to increase image definition is also preferable to study enlarge test specimens: for a gas turbine cooling typical application, tests should be performed in vacuum conditions.

\section{Experimental apparatus}

The experimental apparatus, shown schematically in figure 1, consists of a blowing-type flow circuit, a heater, the test section and a computer-based image-processing system. Two 
rotary vane oil-free vacuum pumps provide a maximum mass flowrate of $0,16 \mathrm{~kg} / \mathrm{s}$. The air enters an electric heater to be heated to a required temperature and then passes through a orifice that measures the flow rate of air. All test rig valves are completely remote controlled in order to set all test parameter by means of the acquisition software.

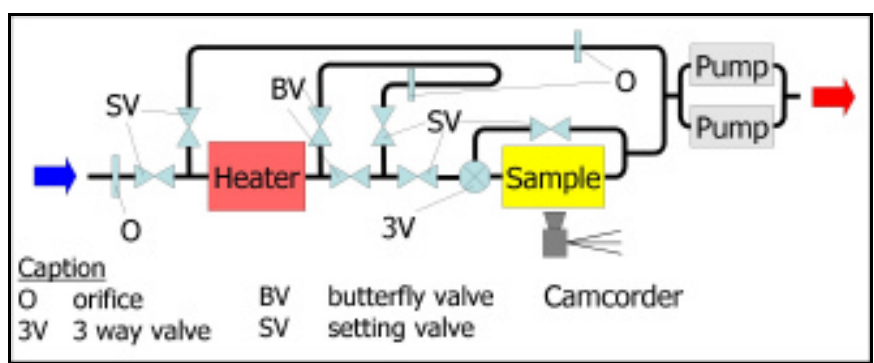

Figure 1 - Experimental apparatus.

\section{Test specimens geometry}

The wedge-shaped test section is made of Plexiglas ${ }^{\circledR}$, while the inserted (pin fins or pedestals) are aluminium made. The wedge angle is $10^{\circ}$ for all geometries. The bottom endwall of a rectangular area with variable dimension for pedestal or pin - fins geometries, representing the heat transfer active surface is sprayed with liquid crystals.

Figure 2 and 3 show, respectively, two samples of pedestal and pin fin test specimens.

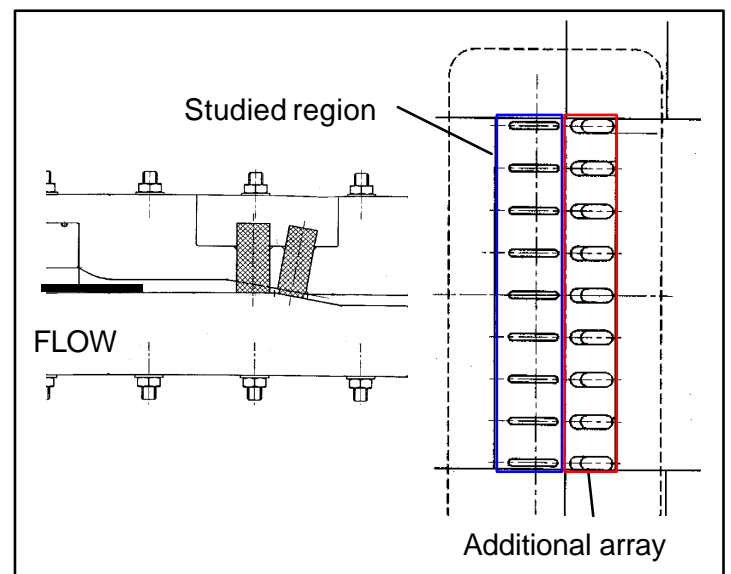

Figure 2 - Example of pedestals geometry.

About pedestals geometries, we studied five configurations differing only for pedestals pitch hence for pedestals number being constant the endwall dimension (table 1). Endwall dimensions are $40 \times 200 \mathrm{~mm}^{2}$, its height is $11.11 \mathrm{~mm}$ at the inlet section and $4.06 \mathrm{~mm}$ at the outlet one. The other investigated geometry features staggered pin - fins arrays. In this case we studied three test specimens differing for pin diameter and pin height (table 2). All pin fins configurations have the same streamwise pitch $(14.55 \mathrm{~mm})$, spanwise pitch
$(16.80 \mathrm{~mm})$, endwall dimension $\left(72.75 \times 200 \mathrm{~mm}^{2}\right)$ and the same pin number $(5 \times 12)$. Both geometries have high pitch - height ratio (i.e. high solidity). Such values together with the wedge shaped duct were not frequently investigated. For both geometries the duct entry length upstream the test section is $170 \mathrm{~mm}$.

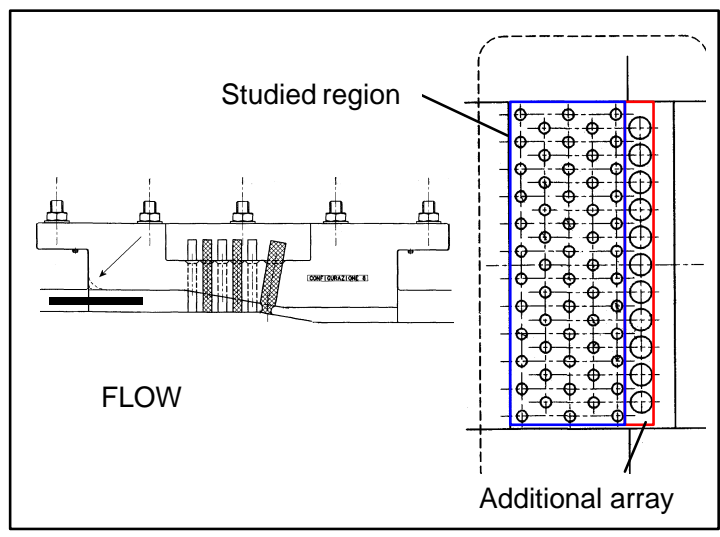

Figure 3 - Example of pin - fins geometry.

Downstream the investigated region all studied models have an additional turbulator array (figure 2 and figure 3): they don't belong to the endwall test region but their presence is fundamental in order to control mainstream mass flow rate.

\begin{tabular}{|c|c|c|c|c|}
\hline \multirow[b]{2}{*}{ Configuration } & \multicolumn{4}{|c|}{ PEDESTAL } \\
\hline & $\begin{array}{c}\text { Length } \\
{[\mathrm{mm}]}\end{array}$ & $\begin{array}{l}\text { Width } \\
{[\mathrm{mm}]}\end{array}$ & $\begin{array}{l}\text { Pitch } \\
{[\mathrm{mm}]}\end{array}$ & Number \\
\hline 1 & \multirow{5}{*}{28} & \multirow{5}{*}{4} & 8 & 25 \\
\hline 2 & & & 16 & 13 \\
\hline 3 & & & 24 & 9 \\
\hline 4 & & & 32 & 7 \\
\hline 5 & & & 40 & 5 \\
\hline
\end{tabular}

Table 1 - Pedestal geometry

\begin{tabular}{cccc}
\hline Configuration & $\begin{array}{c}\text { Pin } \\
\text { diameter } \\
{[\mathbf{m m}]}\end{array}$ & $\begin{array}{c}\text { Endwall inlet } \\
\text { height [mm] }\end{array}$ & $\begin{array}{c}\text { Endwall } \\
\text { outlet height } \\
{[\mathbf{m m}]}\end{array}$ \\
\hline 1 & 5.60 & 18.51 & 5.69 \\
\hline 2 & 6.72 & 19.65 & 6.82 \\
\hline 3 & 8.40 & 21.36 & 8.53 \\
\hline
\end{tabular}

Table 2 - Pin - fins geometry

Both geometries has been investigated for a lot of Reynolds number values comprised between 9000 and 27000 in order to satisfy similitude conditions. The test Reynolds number has been defined at the outlet section of the investigated endwall. For pedestal geometry Reynolds number is based on the hydraulic diameter of the duct enclosed between to turbulators while for pin- fins on pin diameter. Each experimental test has been replicated twice for each Reynolds number with hot air or at room - temperature air in order to 
evaluate respectively heat transfer coefficient distribution and pressure losses. Outlet Mach number of each test was set to 0.3.

\section{Instrumentation arrangement}

Into the test section are located several thermocouples ("T" type, uncertainty less than $0.5 \mathrm{~K}$ ), static pressure taps and some Kiel probes ("KAA" type, United Sensor ${ }^{\circledR}$ ) in order to measure in detail the mainstream temperature and pressures. Figure 4 and figure 5 show the instrumentation arrangement of pedestals and pin - fins geometries: $T$ is for thermocouple, PPS for static pressure tap and $\mathrm{K}$ for Kiel prob.

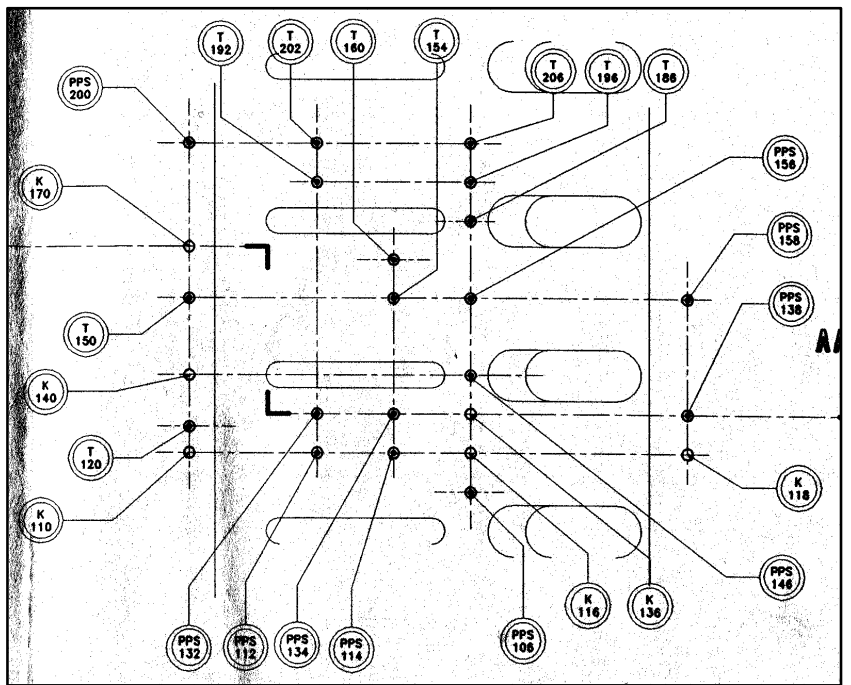

Figure 4 - Pedestals instrumentation arrangement

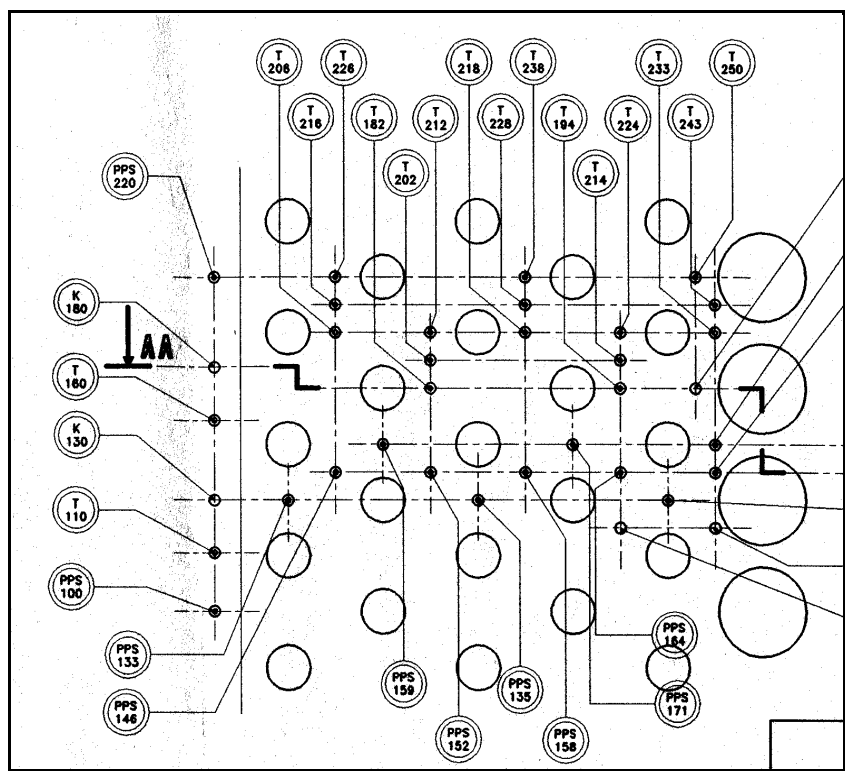

Figure 5 - Pin - fins instrumentation arrangement

A Data Acquisition Switch Unit (HP/Agilent ${ }^{\circledR}$ 34970A) records the time-dependent mainstream temperatures with external cold junction. In addition the pressure taps and Kiel probes are connected to two pressure scanners Scanivalve ${ }^{\circledR}$ DSA 3017 with temperature compensated piezoresistive pressure sensors. The knowledge of time-dependent mainstream temperatures and pressures is fundamental both for TLC technique application and for actual test Reynolds number evaluation.

To get some information about the turbulator surface contribution to global heat transfer coefficient, both pedestals and pin - fins, manufactured by high conductivity material (aluminium), have internally inserted thermocouples. They have been used to measure the time-dependent temperature of the turbulators during transient test in order to evaluate an areaaveraged heat transfer coefficient on their lateral surface.

The pin fin has only one embedded thermocouple, while the pedestal three. In this case, because of higher aspect ratio of the pedestal, the use of a single thermocouple would not be enough to correctly evaluate the aluminium temperature distribution.

\section{Experimental Procedure}

Before the test run, the hot air bypasses the test section so that the endwall remains at laboratory ambient temperature. The flow is kept in diversion until the required mainstream temperature has been achieved, typically at about $70-80^{\circ} \mathrm{C}$. Then, the 3-way valve turns to route the hot air into the test section and, simultaneously, the recorder is switched on to record the mainstream temperature history. The imageprocessing system records the transition time for maximum value of TLC intensity and transfers the data into a matrix of time of the colour change over the entire surface. Time and temperature data are transferred into a computer program to obtain the local heat transfer coefficient. The digital camcorder $\left(\mathrm{CANON}^{\circledR} \mathrm{XM}-1\right)$ uses a optical fiber ring-light system (SchottFostec $^{\circledR}$ KL1500 LCD) that allows to maintain constant both light power and colour temperature. Moreover the use of such light source assures that the light beam is always in line with the camcorder lens.

\section{Endwall heat transfer coefficient evaluation}

The local heat transfer coefficient over the test surface can be obtained by assuming one-dimensional transient conduction over a semi-infinite solid $(1,16)$,

$$
k \frac{\partial^{2} T}{\partial x^{2}}=\rho c_{p} \frac{\partial T}{\partial t}
$$

for which the initial condition and boundary conditions on the liquid crystal coated surface are:

$$
\begin{array}{lll}
t=0 & T(x, t)=T_{i} \\
\forall t \leq \bar{t} & k \frac{\partial T(x, t)}{\partial x}=h \cdot\left(T_{w}(t)-T_{\infty}(t)\right) & \text { at } x=0 \\
\forall t & T(x, t)=T_{i} & \text { as } x \rightarrow \infty
\end{array}
$$

where: 
- $T_{i}$ is the initial room temperature;

- $T_{8}$ is the time-dependent mainstream flow temperature measured by thermocouples;

- $T_{w}$ is the local time-dependent endwall temperature measured by TLC in its activation range;

- $\bar{t}$ is the integration time i.e. the time required to reach TLC maximum intensity at any location of coatedsurface. The TLC temperature at its maximum intensity is known from calibration procedure.

Hence the heat transfer coefficient $h$ is calculated by resolving the 1-D unsteady Fourier equation from time zero (i.e. 3 -way valve is switched and hot air starts to flow into the test section) to the time $\bar{t}(1,16)$.

The testing time is about $60-150 \mathrm{~s}$ depending on the test specimens and mainstream temperature: it is so short that the heat flow can hardly penetrate into the Plexiglas ${ }^{\circledR}$ plate (the material has a very reduced heat conductivity), so as to ensure the validity of the assumption of the semi-infinite solid on the test surface (17).

\section{$\underline{\text { Turbulator heat transfer coefficient evaluation }}$}

Being pedestals and pin fins aluminium made, during tests their own temperature raise was measured by thermocouples.

To evaluate an area-averaged heat transfer coefficient on the inserted surface, a unsteady 2D / 3D FEM analysis was conducted using a commercial code $\left(\right.$ ANSYS ${ }^{\circledR}$ 5.7). The boundary conditions supplied are directly reached from experimental tests. Particularly the flow and the endwall timetemperature history are supplied together with the local heat transfer coefficient value on the endwall surface. Then, using a iterative approach, a heat transfer coefficient on the turbulator surface was set in order to match the calculated temperature history of the aluminium inserted with the measured one.

Figure 6 and figure 7 show two example of unsteady FEM calculation results, respectively for a pin fin and a pedestal configuration. For the first kind of turbultor, thanks to its symmetry, a 2D calculation was performed while for pedestal we were forced to used a 3D calculation.

FEM analysis allowed to point out the effects of metal inserted on the temperature distribution into the endwall thickness. Close to the metal turbulator there is a isothermal distortion: in this region the heat conduction is not strictly 1D and the numerical approach previously described could net be used. Besides the comparison we performed with other tests where we used Plexiglas turbulators (i.e. absence of heat sink into the test section) confirms that there is not significantly variation of the endwall heat transfer coefficient.

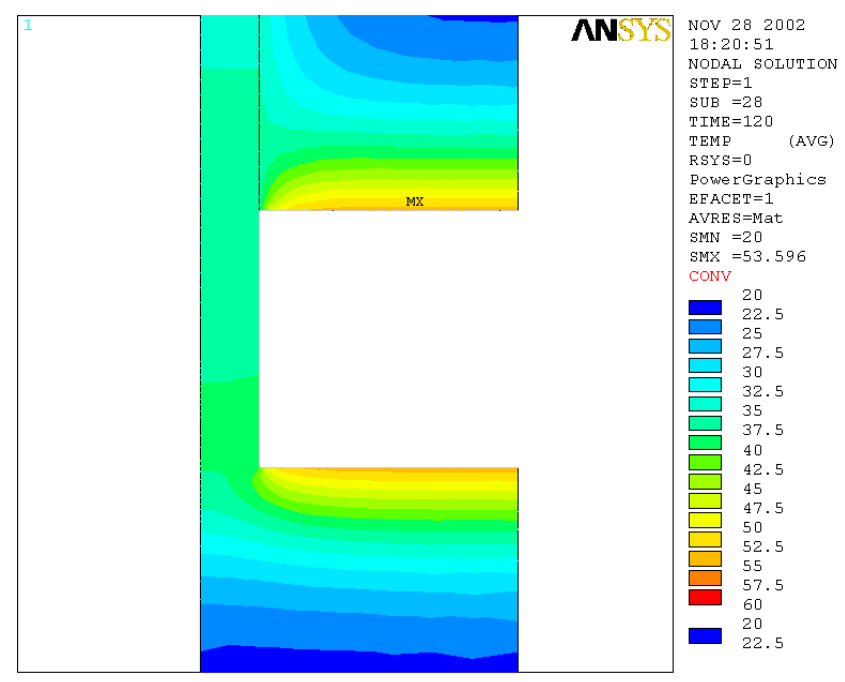

Figure 6 - Temperature distribution (pin-fin, geometry\#7).

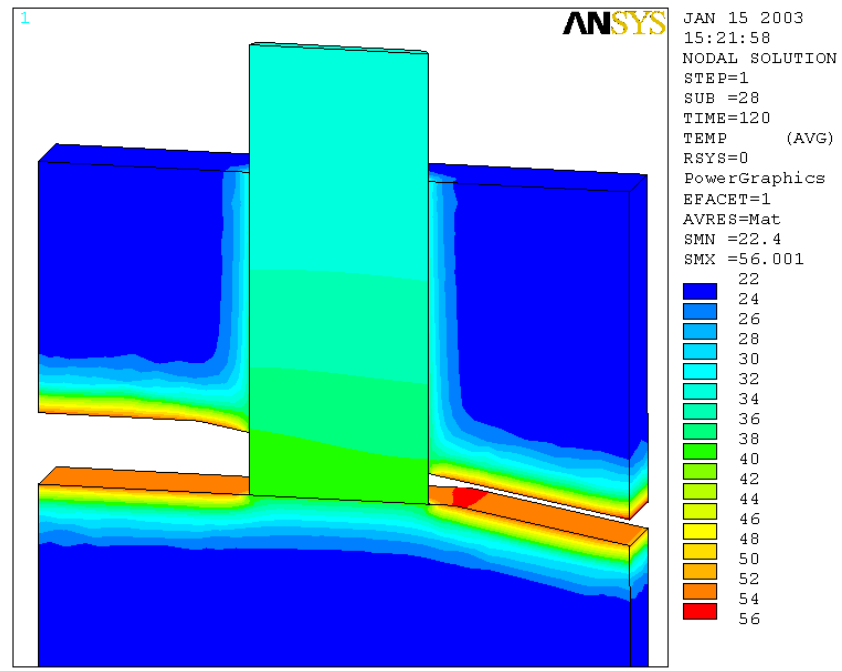

Figure 7 - Temperature distribution (pedestal, geometry\#3).

\section{Experimental Uncertainty}

The uncertainty analysis was performed following the procedure proposed by Moffat (18). The individual contributions to the uncertainties of the single parameters for each of the measured physical properties are summarised in table 3. The estimated maximum uncertainties of the investigated parameters are shown in table 3 . 


\begin{tabular}{|c|c|c|}
\hline \multicolumn{2}{|r|}{ Variable } & \multirow{2}{*}{$\begin{array}{c}\text { Uncertainty } \\
1.0 \% \\
\end{array}$} \\
\hline$D_{h}$ & Hydraulic diameter & \\
\hline$\sqrt{\rho}$ & $\begin{array}{l}\text { Plexiglas properties } \\
\text { coefficient }\end{array}$ & $5.0 \%$ \\
\hline$\Delta \mathrm{t}$ & Time of colour change & $1.1 \%$ \\
\hline $\mathrm{T}$ & main stream temperature & $0.3 \%$ \\
\hline \multirow[t]{3}{*}{$T_{i}$} & Initial temperature & $0.2 \%$ \\
\hline & $\begin{array}{l}\text { TLC temperature at its } \\
\text { maximum intensity }\end{array}$ & $0.2 \%$ \\
\hline & $\begin{array}{l}\text { Time required to reach TLC } \\
\text { maximum intensity }\end{array}$ & $1.1 \%$ \\
\hline$A$ & Cross section & $1.0 \%$ \\
\hline$\dot{\mathrm{m}}$ & Air mass flow rate & $2.0 \%$ \\
\hline$\Delta p$ & Difference pressure & $0.2 \%$ \\
\hline$\mu$ & dynamic viscosity of air & $1.2 \%$ \\
\hline$\rho$ & Air density & $0.5 \%$ \\
\hline $\mathrm{h}$ & heat transfer coefficient & $12.2 \%$ \\
\hline $\operatorname{Re}$ & Reynolds number & $2.8 \%$ \\
\hline $\mathrm{K}_{\mathrm{s}}$ & pressure drop coefficient & $5.4 \%$ \\
\hline
\end{tabular}

TABLE 3 - Uncertainty analysis

\section{RESULTS AND DISCUSSIONS}

In this section of the paper the results concerning our experimental survey are discussing both in terms of heat transfer coefficient and Nusselt number. It is based on the total temperature while the flow thermodynamic quantities are calculated at the film temperature. TLC experimental results are compared with correlations. It is important to stress that only seldom it has been possible to find very suitable correlations. About pedestal geometries we referred to correlations produced for constant - section duct, both for heat transfer calculation and pressure drops evaluation. About the other geometry, staggered pin - fins inserted in wedge - shaped duct, we were able to found some very useful works which allowed to perform more suitable comparisons $(8,14,15)$.

The turbulence level at the test section inlet has been controlled by inserting a classical turbulence manipulator some diameters upstream the investigated region. We used a metal mesh with square - shaped holes $(6.0 \mathrm{~mm}$ side) able to assure a turbulence level of $5 \%$ during the test. The evaluation of turbulence level has been computed by correlation approach $(19,20)$ and confirmed by experimental tests performed for a suitable Reynolds number variation range (21).

\section{Pedestals}

We investigated five different configurations (table 1), each one for five different values of Reynolds numbers:

$$
R e_{D_{h}}=\frac{\dot{m}}{A} \cdot \frac{D_{h}}{\mu}
$$

where the hydraulic diameter

$$
D_{h}=4 \cdot \frac{A}{p}
$$

In table 4 configuration\#3 tests Reynolds numbers are listed. They are based on hydraulic diameter of the duct comprised between two contiguous pedestals and respectively calculated at the outlet section and at the average section of the pedestal array.

\begin{tabular}{ccc}
\hline Test number & Outlet $\mathbf{R e}$ & Averaged $\mathbf{R e}$ \\
\hline 1 & 10300 & 9580 \\
\hline 2 & 15050 & 13970 \\
\hline 3 & 19900 & 18480 \\
\hline 4 & 23500 & 21820 \\
\hline 5 & 28090 & 26070 \\
\hline
\end{tabular}

TABLE 4 - Test Reynolds number (configuration\#3)

\section{Heat transfer}

Figure 8 shows for configuration\#3 the Reynolds number effect on local heat transfer distributions on the endwall surface of the straight wedge duct with a pedestal array.

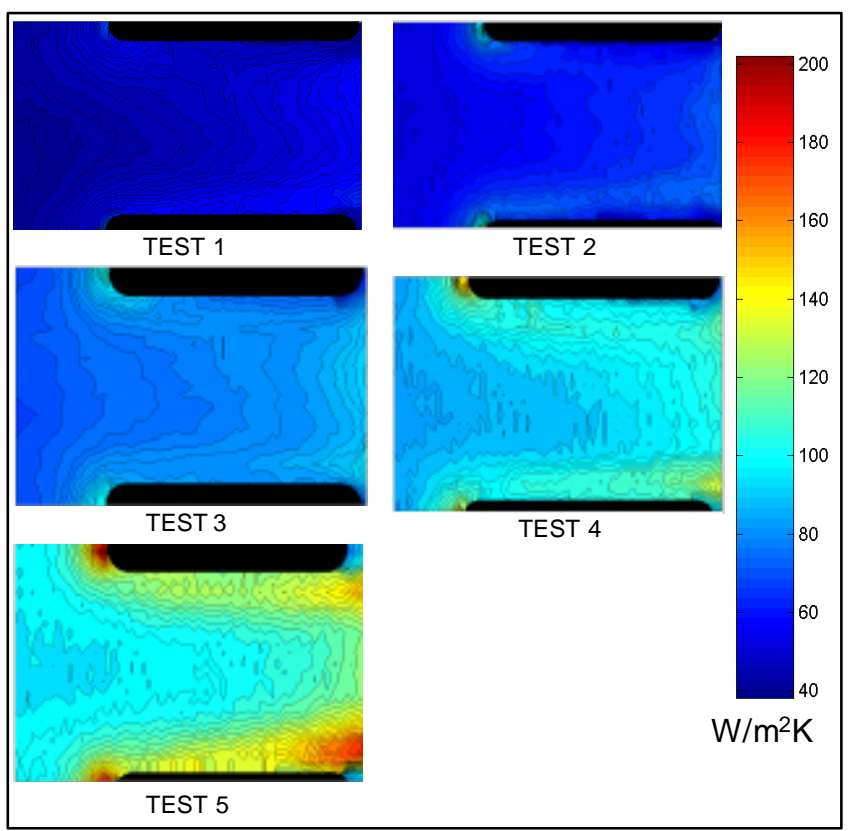

\section{Figure 8 - Local endwall HTC (Pedestal - configuration\#3)}

Qualitatively the endwall HTC distribution is the same for every test but its value increases with Reynolds number. Close to the duct centre, where pedestal presence effect is not felt, the endwall HTC value raise in streamwise direction is due only to the duct section reduction i.e. to the flow acceleration (figure 9). Close to the pedestal, where a passage vortex is present, there is a endwall HTC augmentation (figure 10). In particularly the endwall HTC reaches its maximum value upstream the pedestal leading edge (at the stagnation point) and at the pedestal outlet 
section (figure 8). This last phenomenon is due to the interaction between the vortex and the pedestal of the additional array (figure 2).

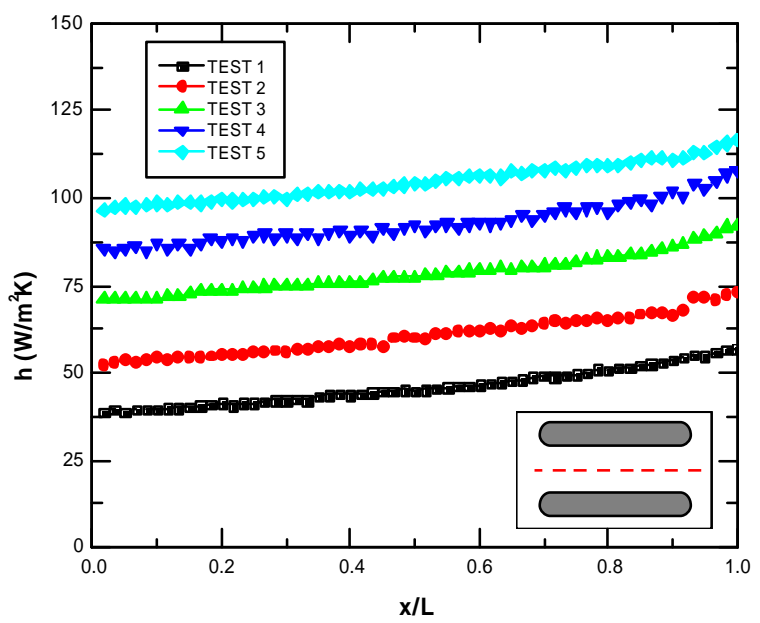

Figure 9 - Endwall HTC (Pedestal - configuration\#3) in duct centre (streamwise direction)
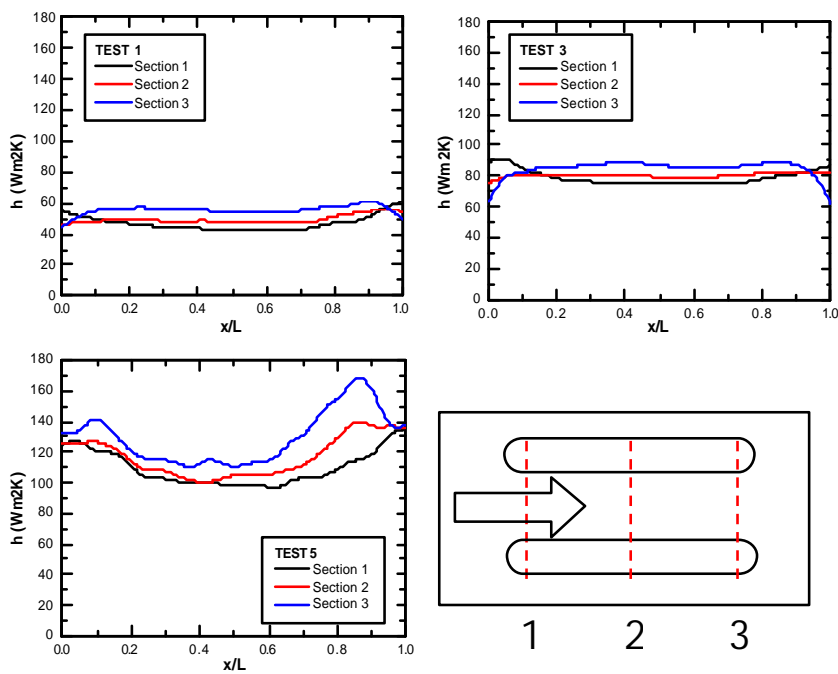

\section{Figure 10 - Endwall HTC (Pedestal - configuration\#3) in spanwise direction.}

Figure 10 shows for configuration\#3 the endwall HTC distribution in spanwise direction for three different sections. The local HTC value increases with the test Reynolds number value and for each section close to the pedestal it reaches its maximum value because of secondary flows presence.

All studied geometries showed the same endwall HTC behaviour by varying Reynolds number value. It is important to stress that for the pedestal geometry with more reduced pitch value the secondary flows fill almost totally the duct, so the endwall HTC is high in the duct centre too. On the contrary, the configuration with the highest pitch value presents a very large portion of the duct not influenced from secondary flows presence.

Figure 11 shows a global comparison for all studied configurations, both for area - averaged endwall Nusselt number and pedestal Nusselt number as a function of the average Reynolds number. Area - averaged is for the HTC which has been averaged on endwall area or pedestal surface. Moreover both Nusselt and Reynolds numbers are based on duct - averaged hydraulic diameter. The experimental analysis allowed to point out that the pedestal surface considerably contributes to the global heat transfer: for each configuration the pedestal Nusselt number value is about 3.0 - 5.0 times the endwall one.

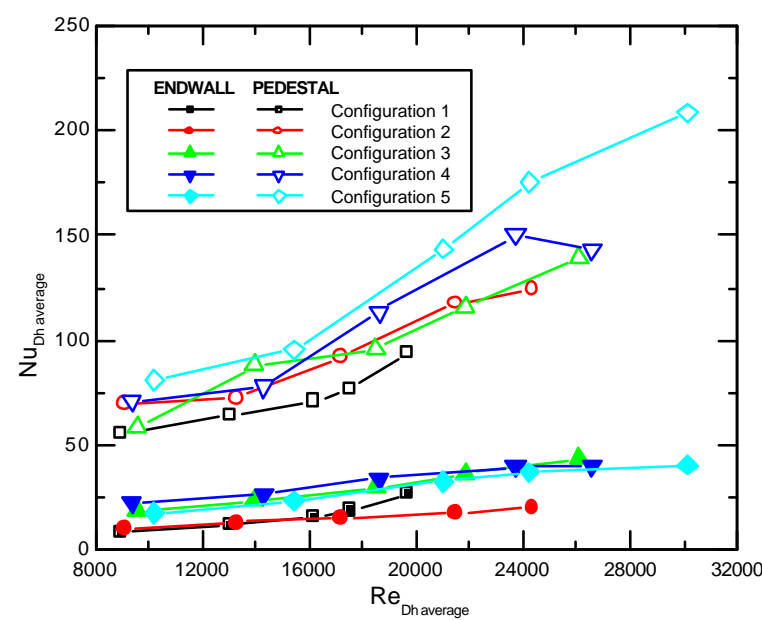

Figure 11 - Endwall and pedestal area - averaged $\mathrm{Nu}_{\text {Dh }}$ vs. ductm - average $\mathbf{R e}_{\mathrm{Dh}}$.

More useful it is the evaluation of the total area averaged Nusselt number value and its comparison with correlation results. Nusselt number was calculated as a weighted - average by using the surface as weight. Figure 12 shows the total area - averaged Nusselt number versus average Reynolds number, concerning both our experimental measurements and Gnielinski correlation results.

The comparison shows that our experimental results well agree with Gnielinski correlation (35),

$$
N u_{D_{h}}=0.0214 \cdot\left(\operatorname{Re}_{D_{h}}{ }^{0.8}-100\right) \cdot \operatorname{Pr}^{0.4}
$$

developed for constant section smooth duct and fully developed turbulent flow. Then it is evident that the experimental Nusselt number can be correlated as $N u=A \cdot R e^{k}$ with both the Reynolds number exponent and the multiplicative factor $A$ very close to the Gnielinski correlation ones. 


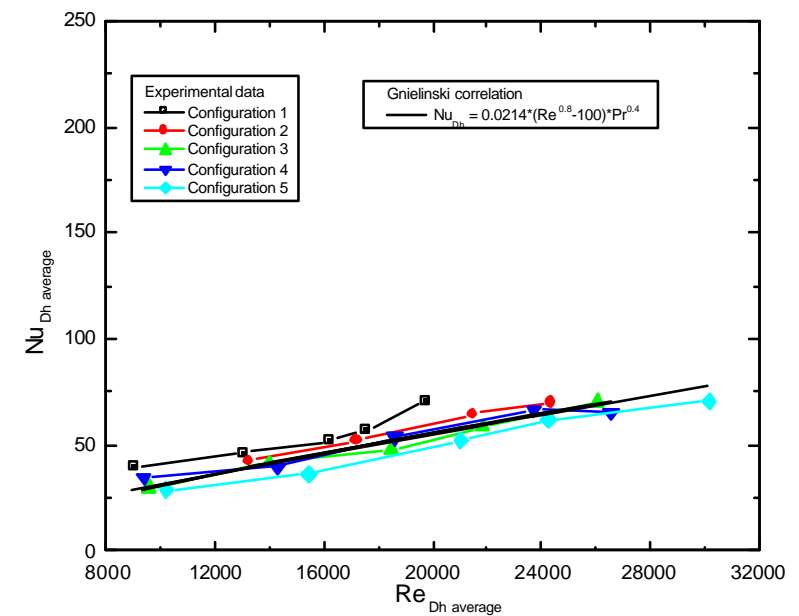

Figure 12 - Total area - averaged $\mathrm{Nu}_{\mathrm{Dh}}$ vs. duct average $\boldsymbol{e}_{\mathrm{Dh}}$ (experimental and correlation).

\section{Pressure losses}

Pressure drops were measured along the duct in adiabatic condition (mainstream flow at room temperature). Experimental data were reduced in terms of $K_{s}$ pressure factor:

$$
K_{s}=\frac{\left(p_{0 \text { in }}-p_{0 \text { out }}\right)}{\rho v^{2} / 2}
$$

for both studied geometries. The total pressure values used in equation 8 were measured respectively upstream and downstream the studied region (figure 2) for both pedestal and pin fin geometries. The definition of the velocity value used in equation 8 is different for the two geometries. For pedestal the velocity is related to the section upstream the turbulators, while for pin fin is the maximum value at the first row.

We compared our experimental results with a classical correlation developed for rectangular smooth duct and fully developed flow (22):

$$
K_{s}=\frac{L}{D_{h}} \cdot 0,316 \cdot R e_{D_{h}}^{-025}
$$

Figure 13 shows pressure factor trend versus the average Reynolds number for configuration\#3. We measured very significant pressure drops due to inlet and outlet concentrated losses, unlike the correlations that is able to predict only the smooth duct friction. For the other pedestal configurations we got similar results and generally measured pressure drops are higher for the configurations with more reduced pitch.

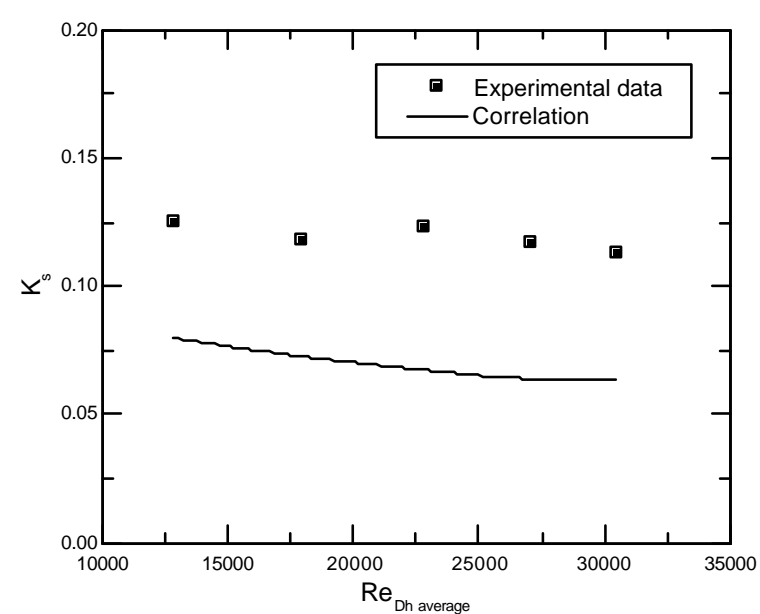

Figure 13 - Pressure factor vs. duct - average $\mathbf{R e}_{\mathrm{Dh}}$ (experimental configuration\#3 and correlation).

\section{Pin fins}

We investigated three different configurations (table 2), each one for five different values of Reynolds numbers. Two kinds of Reynolds numbers are discussed herein to examine their effects on the heat transfer and pressure drop characteristics in pin-fins wedge ducts. The first one is based on the mean velocity and the equivalent hydraulic diameter at the wedge duct entrance (equation 5 and equation 6), the other one is based on the maximum velocity in the pin-fin wedge and the pin diameter:

$$
R e_{d}=\frac{\rho v_{M A X} d}{\mu}
$$

In table 5 configuration\#2 tests Reynolds numbers are listed. They are based on pin diameter and respectively calculated for the maximum velocity at the last pin row (outlet) and at the third row (averaged).

\begin{tabular}{ccc}
\hline Test & Outlet Re & Averaged Re \\
\hline 1 & 9950 & 7144 \\
\hline 2 & 14000 & 10043 \\
\hline 3 & 19700 & 14152 \\
\hline 4 & 22000 & 15866 \\
\hline 5 & 26600 & 19121 \\
\hline
\end{tabular}

\section{TABLE 5 - Test Reynolds number (configuration\#2)}

\section{Heat transfer}

About pin - fins turbulators, several literature sources show that they are very efficient turbulence promoters: their effect tends to increase starting from first array to the fourth or fifty array where the endwall HTC reaches its maximum value. This trend is well confirmed from our experimental results. Figure 4 shows, for configuration\#2, the Reynolds-number effect on local heat transfer distributions on the endwall surface of the straight wedge duct with staggered pin - fins arrays. 


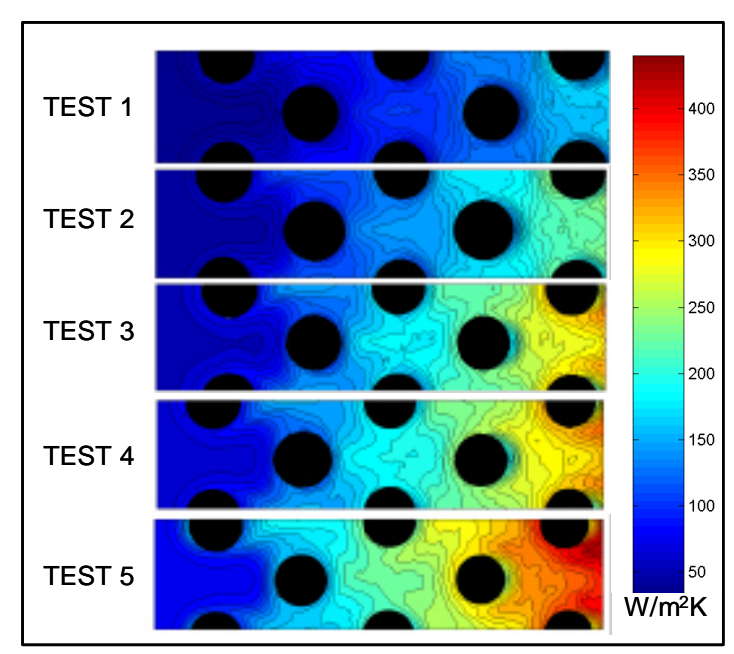

Figure 14 - Local endwall HTC (Pin fins configuration \#2).

The local endwall HTC increases in streamwise direction and its maximum value is located at the last pin row. This phenomenon is due both to the interaction of various secondary flows and flow acceleration effect.

The HTC distribution around the pin is the well known one: the presence of very complex secondary flows, among they a horse - shoe vortex, determines high HTC value in front of the turbulator, at the stagnation point, and lower values behind (figure 14). This last phenomenon is due to the flow separation downstream the pin and it is particularly evident for the fourth and fifth array (figure 14). This HTC behaviour for configuration\#2 is described in figure 15 where the local endwall HTC course in streamwise direction is shown as a function of dimensionless duct length. The local endwall HTC increases monotonically in streamwise direction for every test. The same results are shown in figure 16 in terms of row - averaged endwall HTC as a function of pin row number.

Figure 17 shows row - averaged endwall Nusselt number behaviour versus local Reynolds number. Both dimensionless numbers are based on pin diameter. For each Reynolds number, i.e. for each test, last pin row performs the maximum Nusselt number value.

Together with endwall HTC evaluation, our experimental survey dealt with pin heat transfer coefficient evaluation in order to compute the effective heat transfer towards the turbulators. Figure 18 shows for configuration\#2 a comparison between row - averaged endwall Nusselt number and pin Nusselt number as function of local Reynolds number. The experimental data are related to the third pin row.

The results show that although pin Nusselt number is very high if compared with the endwall one, the total value (i.e. the area-averaged value) is very close to the second.

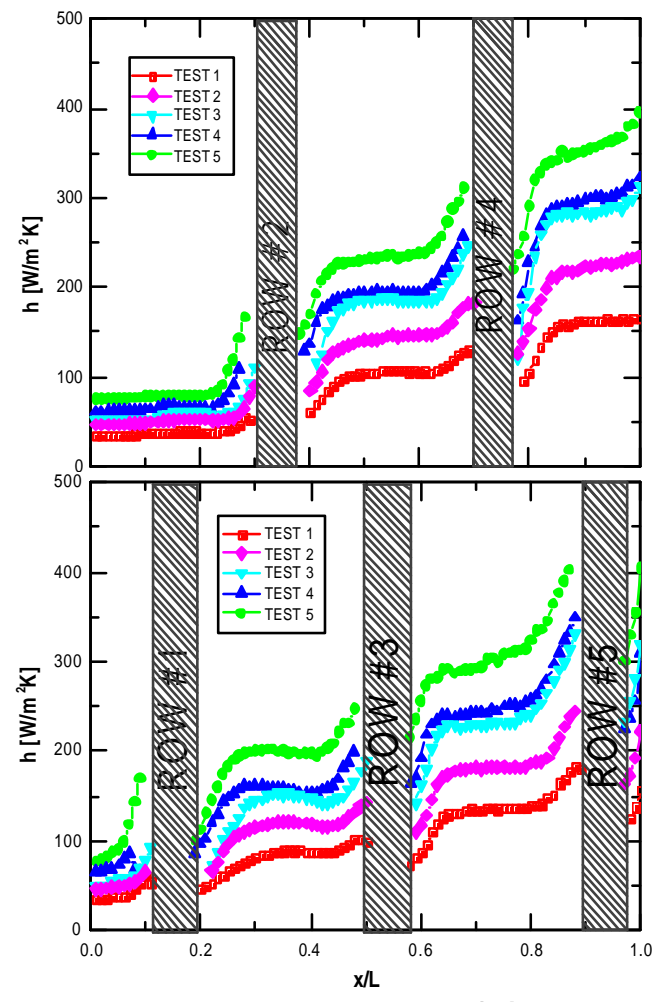

Figure 15 - Local endwall HTC (Pin fins configuration\#2).

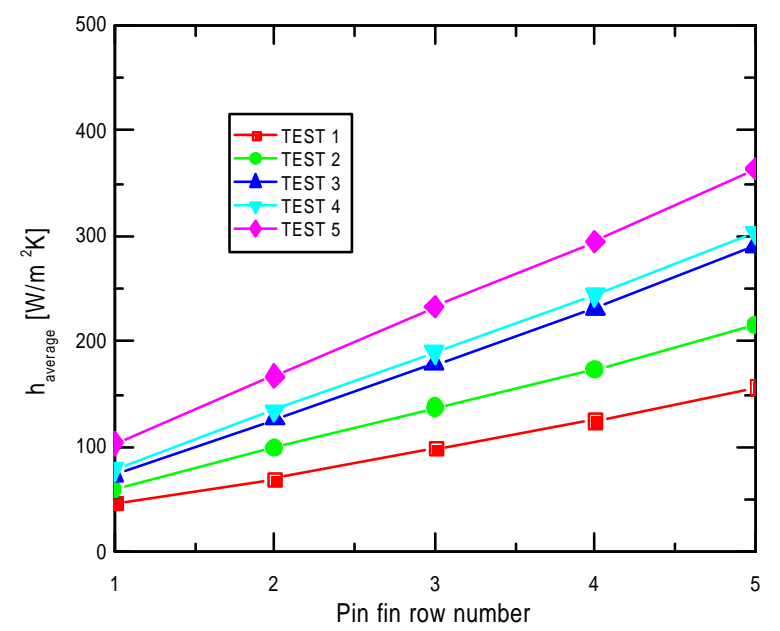

Figure 16 - Row - averaged endwall HTC (Pin fins configuration\#2).

The experimental results just herein discussed in terms of row - averaged values, can be also described in terms of areaaveraged ones in order to perform some useful comparisons with suitable correlations. In figure 19 the area - averaged Nusselt number is shown as a function of row - averaged Reynolds number for every configurations. At fixed Reynolds, the Nusselt values are practically the same for all configurations. 


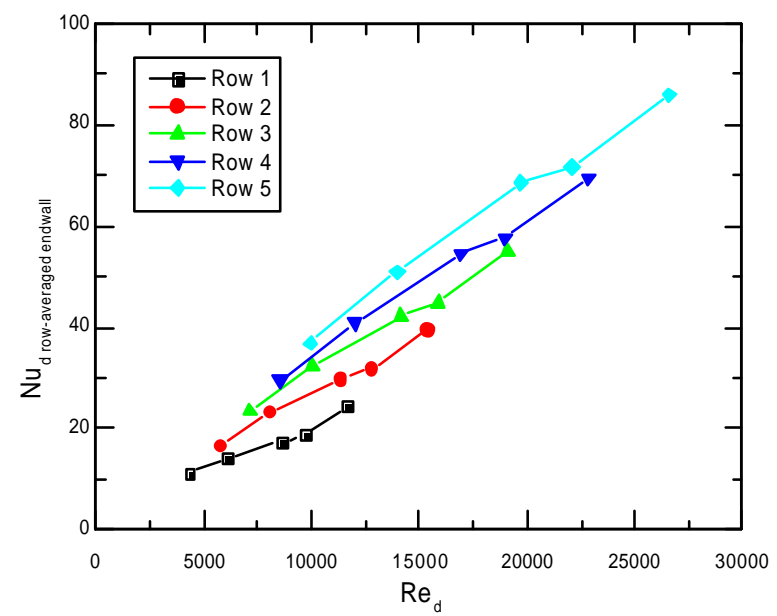

Figure 17 - Row - averaged endwall $\mathrm{Nu}_{d}$ (Pin fins configuration \#2) vs local $\mathbf{R e}_{\mathrm{d}}$.

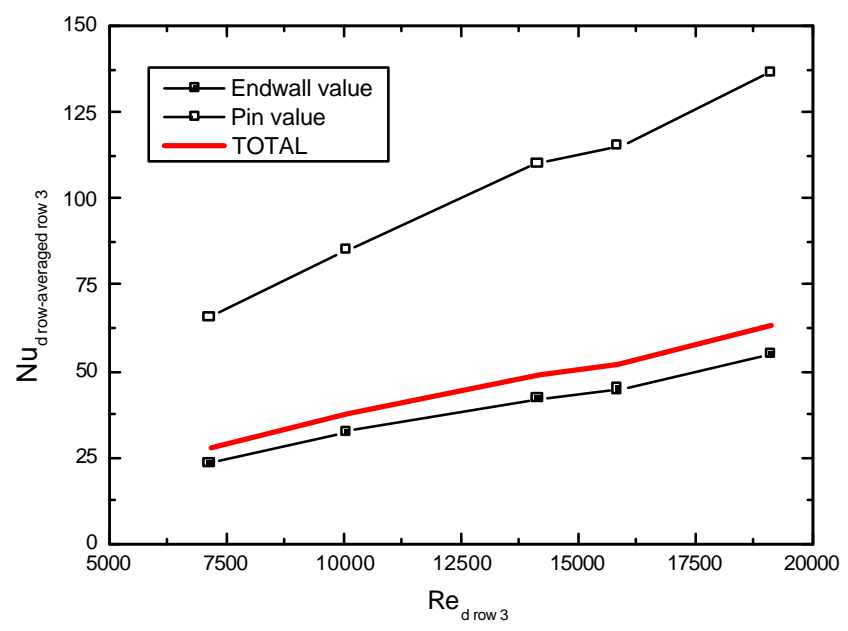

Figure 18 - Row - averaged endwall $\mathrm{Nu}_{d}$ (Pin fins configuration\#2) vs local $R_{d}-$ Row\#3.

An useful comparison between our experimental results and published correlations can be performed using the following correlation (15),

$$
N u_{D_{h}}=0289 \cdot R e_{D_{h}}{ }^{0.651}
$$

developed for five row staggered - pin fins inserted in a wedge - shaped duct. This correlation allows to determine the area - average Nusselt number as function of Reynolds number, both based on the equivalent hydraulic diameter at the wedge duct entrance.

Figure 20 shows a comparison between experimental data related to configuration\#2 and the correlation results: even if the correlation has been performed for a slightly different pin fins arrangement, the agreement with experimental data is good.

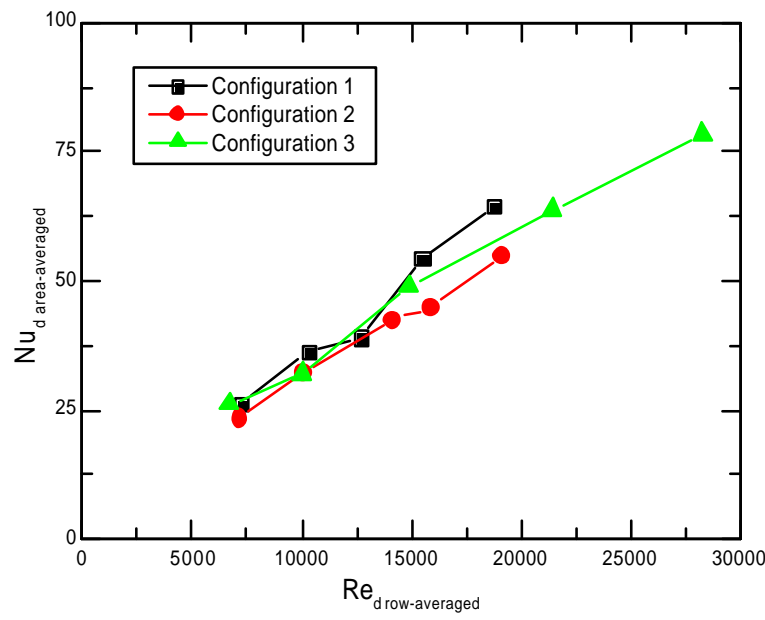

Figure 19 - Area - averaged endwall $\mathrm{Nu}_{\mathrm{d}}$ (all configurations) vs local $\mathbf{R e}_{\mathrm{d}}$.

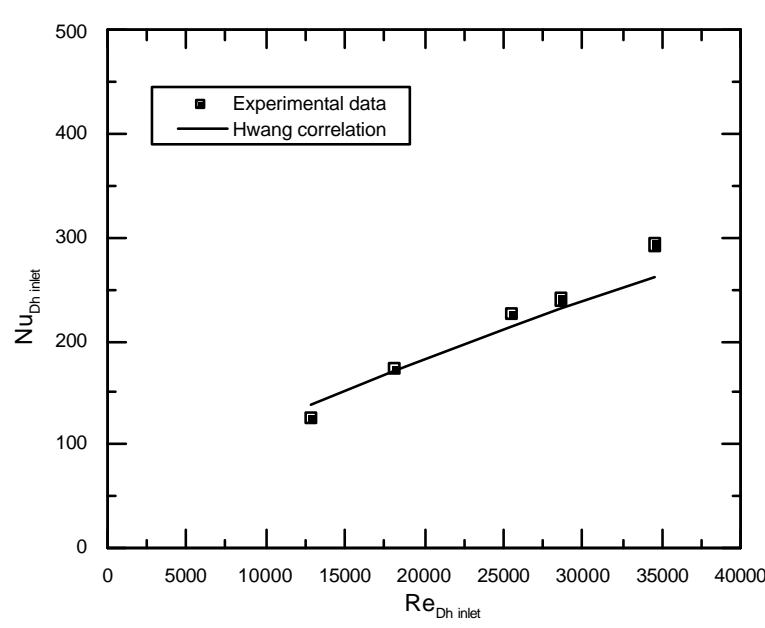

Figure 20 - Area - averaged endwall $\mathrm{Nu}_{\text {Dh inlet }}$ (configuration\#2) vs $\mathrm{Re}_{\mathrm{Dh} \text { inlet }}$.

\section{Pressure losses}

Pressure drops have been measured along the duct in adiabatic condition (mainstream flow at room temperature). Experimental data have been reduced in terms of the $K_{s}$ pressure factor (equation 8 ).

We compared our experimental results with a classical correlation developed for staggered pin fin inserted in constant section duct (8):

$$
K_{s}=1268 \cdot N \cdot R e_{d}^{-0,132}
$$

Figure 21 shows pressure factor trend versus the Reynolds number based on pin diameter for configuration\#2. Our experimental results agree with correlation results and for the other pin fin configurations we got similar results. 


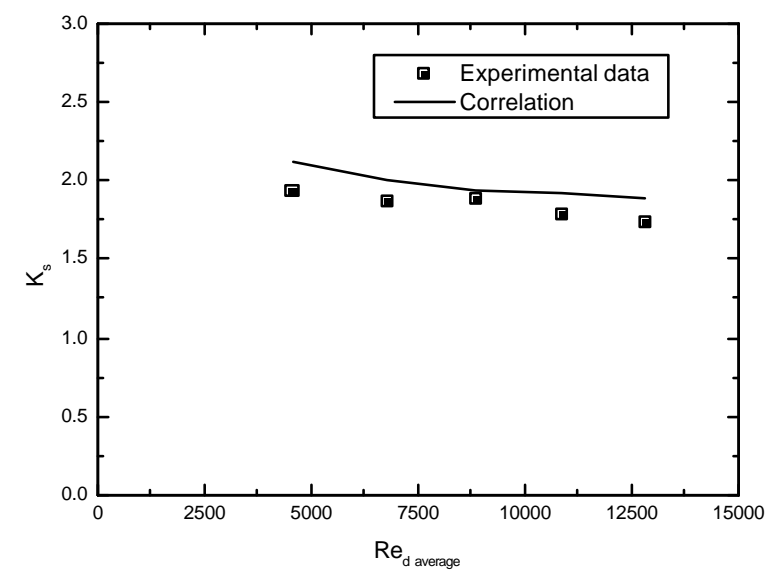

Figure 21 - Pressure factor vs. row\#1 $\mathbf{R e}_{\mathrm{d}}$ (experimental configuration\#2 and correlation).

\section{PERFORMANCES COMPARISON}

Figure 2 shows the comparison between the Nusselt number ratio and the pressure factor ratio for pedestal configuration\#3 and pin configuration\#2. Nusselt numbers are both based on the mean velocity and on the equivalent hydraulic diameter at the wedge duct entrance.

The straight wedge duct with staggered pin fins seems be very attractive in terms of heat transfer thank to its higher heat transfer coefficient. Besides pin fins determines a very high pressure drop if compared with the pedestals one.

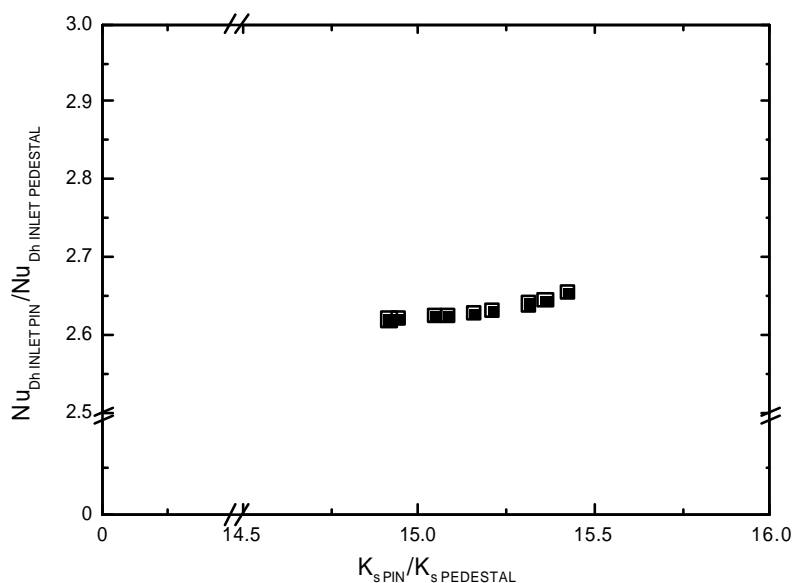

Figure 22 - Comparison between $\mathrm{Nu}$ ratio and $\mathrm{K}_{\mathrm{s}}$ ratio for pedestal configuration\#3 and pin configuration\#2.

\section{CONCLUSIONS}

In this paper an experimental analysis with TLC technique, applied to internal gas turbine blade cooling system is showed. Attention is focused to TE zone with low thickness and high aspect ratio. Wedge duct are studied for both long pedestal and pin fins array insertion.
Heat transfer contribution on turbulators surface is also evaluated and it appears greater for long pedestals.

Results are compared with standard correlation in order to validate experimental results: generally the agreement is good both for heat transfer and pressure drop. Results indicate that the smallest long ribs pitch and pin fin diameter are most recommended because of their higher endwall heat transfer and moderate pressure-drop enhancement.

The study of different configuration for each kind of turbulator can allow to produce useful correlations for advanced design of TE cooling systems.

\section{ACKNOWLEDGMENTS}

The reported work was performed within a research project that is part of the European project "Aerothermal Investigation of Turbine Endwalls and Blades" (AITEB, 5FP, G4RD-CT-1999-00055). The permission for the publication is gratefully acknowledged by the authors.

We wish to thank our colleagues M. Surace and L. Vannuci and Dr. D. Coutandin of Fiat Avio for always useful discussions and valid suggestions.

\section{REFERENCES}

1. Ekkad, S.V., and Han, J.C., 1997, "Detailed heat transfer distributions in two -pass square channels with rib turbulators" Int. J. Heat and Mass Transfer, vol.40, No. 11, pp.2525-2537

2. Gillespie, R.H., Ireland, P.T., Dailey, G.M., 2000, "Detailed flow and heat transfer coefficient measurements in a model of an internal cooling geometry employing orthogonal intersecting channels", TURBO EXPO 2000, Munich, Germany, May 811, ASME Paper 2000-GT-0653

3. Hwang, J., and Lu, C., 2000, "Lateral flow effect on end wall heat transfer and pressure drop in a pin fin trapezoidal duct of various pin shapes", TURBO EXPO 2000, Munich, Germany, May 8-11, ASME Paper 2000-GT-0232

4. Armstrong, J., Winstanley, D., 1988, "A review of staggered array pin fin heat transfer for turbine cooling applications", ASME Journal of Turbomachinery, vol.110, January 1988, pp.94-103.

5. Brigham, B. A., Van Fossen, G. J., 1984, "Length-todiameter ratio and row number effects in short pin fin heat transfer", ASME Journal of Engineering for Gas Turbines and Power, Vol. 106, pp. 241-245.

6. Lau, S. C., Han, J. C., Batten, T., 1988 'Heat transfer, pressure drop, and mass flow rate in pin fin channel with long and short trailing edge ejection holes", ASME Paper 88-GT-42.

7. Metzger, D. E., Berry, R. A., Bronson, J. P., 1981, "Developing heat transfer in rectangular ducts with arrays of short pin fins", ASME Paper No. 82-WA/HT-6.

8. Metzger, D. E., Haley, S. W., 1982, "Heat transfer experiments and flow visualization for arrays of short pin fins", ASME Paper No.82-GT-138.

9. Metzger, D. E., Shepard, W. B., Haley, S. W., 1986, "Row resolved heat transfer variations in pin fin arrays including 
effect of non-uniform arrays and flow convergence", ASME Paper No. 86-GT-132.

10. Abuaf, N., Co hn, A., 1988, "Gas turbine heat transfer with alternate cooling fluids", ASME Paper 88-GT-16.

11. Wang, Z., Ireland, P.T., Jones, T.V., Toby Kohler, S., 1994, "Measurements of local heat transfer coefficient over the full surface of a bank of pedestals with fillet radii", ASME Paper 97GT-307.

12. Wang, Z., Ireland, P.T., Jones, T.V., 1995, "Detailed heat transfer coefficient measurements and thermal analysis at engine conditions of a pedestal with fillet radii", ASME J. of Turbomachinery, vol. 117 , pp. 290-297.

13. Baughn, J.W., Ireland, P.T., Jones, T.V., Saniei, N., 1988, “A comparison of the transient and heated-coating methods for the measurements of local heat transfer coefficients on a pin fin", ASME Paper 88-GT-180

14. Hwang, J., J., Lui, C., C., 1999, "Detailed heat transfer characteristic comparison in straight and 90-deg turned trapezoidal ducts with pin-fins arrays", International Journal of Heat and Mass Transfer, Volume 42, Pages 4005-4016.

15. Hwang, J., J., Lui, C., C., 2001, "Measurement of endwall heat transfer and pressure drop in a pin-fin wedge duct", International Journal of Heat and Mass Transfer, Volume 45, Pages 877-889.
16. Chambers, A., C., Gillespie, D., R., H., Ireland, P., T., 2002, "A novel transient liquid crystal technique to determine heat transfer coefficient distributions and adiabatic wall temperature in a three temperature problem“, ASME Paper GT-2002-30532.

17. Graham, D., and Rhine, J., 2000, "The design of transient wall heating experiments for the determination of convective heat transfer using liquid crystal thermography", ASME Paper 2000-GT-0658.

18. Moffat, R. J., "Contribution to the theory of single-sample uncertainty analysis”, J. Fluid. Eng., 104, 1982, pp 250-260.

19. Groth , J. and Johansson, A. V., 1988, "Turbulence reduction by screens", Journal Fluid Mech., vol. 197, pp. 139155 .

20. Roach, P.E. 1987, "The generation of nearly isotropic turbulence by means of grids", J. Heat Fluid Flow, vol. 8 (2), pp 82-92.

21. Carcasci, C., Facchini B., Innocenti, L., Surace, M., 2002, "Experimental studies on turbulence behind porous foams", 32nd AIAA Fluid Dynamics Conference, 24-26 June, St. Louis, $\mathrm{MO}$

22. Rohsenow, W.M., Hartnett, J.P., Cho, Y.I., "Handbook of heat transfer", McGraw-Hill, 1998, pp. 5.22 - 5.26. 